\title{
Predictive Torque and Rotor Flux Control of a DFIG-dc System for Torque-Ripple Compensation and Loss Minimization
}

DOI:

10.1109/TIE.2018.2818667

\section{Document Version}

Accepted author manuscript

Link to publication record in Manchester Research Explorer

Citation for published version (APA):

Cruz, S., Marques, G., Gonçalves, P., \& lacchetti, M. (2018). Predictive Torque and Rotor Flux Control of a DFIGdc System for Torque-Ripple Compensation and Loss Minimization. IEEE Transactions on Industrial Electronics, 110. https://doi.org/10.1109/TIE.2018.2818667

\section{Published in:}

IEEE Transactions on Industrial Electronics

\section{Citing this paper}

Please note that where the full-text provided on Manchester Research Explorer is the Author Accepted Manuscript or Proof version this may differ from the final Published version. If citing, it is advised that you check and use the publisher's definitive version.

\section{General rights}

Copyright and moral rights for the publications made accessible in the Research Explorer are retained by the authors and/or other copyright owners and it is a condition of accessing publications that users recognise and abide by the legal requirements associated with these rights.

\section{Takedown policy}

If you believe that this document breaches copyright please refer to the University of Manchester's Takedown Procedures [http://man.ac.uk/04Y6Bo] or contact uml.scholarlycommunications@manchester.ac.uk providing relevant details, so we can investigate your claim.

\section{OPEN ACCESS}




\title{
Predictive Torque and Rotor Flux Control of a DFIG-dc System for Torque-Ripple Compensation and Loss Minimization
}

\author{
Sérgio M. A. Cruz, Senior Member, IEEE, Gil D. Marques, Senior Member, IEEE, Pedro F. C. \\ Gonçalves, Student Member, IEEE and Matteo F. Iacchetti, Senior Member, IEEE
}

\begin{abstract}
The severe torque ripple normally occurring in the DFIG-dc system can cause premature failure of mechanical components and shorten the life of the drive train. This paper addresses the torque ripple issue by proposing a predictive direct torque control strategy which delivers at the same time torque ripple suppression and minimization of losses. The existing control algorithms for torque ripple mitigation are mostly based on resonant controllers and repetitive control forcing the compensation signal either through the current chain or directly into the rotor voltage commands. All these techniques lead to structures with multiple controllers whose tuning is not straightforward. Furthermore, they are very sensitive to the operating frequency, making optimized operation with variable frequency highly challenging. Conversely, the proposed algorithm predicts directly the best rotor voltage space vector to minimize torque ripple and track a prescribed rotor flux amplitude to minimize losses, with no current control chain. As confirmed by simulations and experiments, the strategy allows large stator frequency variations as required by the optimal flux command for minimum losses, whilst ensuring effective torque ripple compensation.
\end{abstract}

Index Terms- Doubly fed induction generators (DFIG), induction generators, torque ripple compensation, predictive control, loss minimization.

\section{NOMENCLATURE}

General

$\begin{array}{ll}g & \text { Cost function. } \\ \mathbf{i}_{s}, \mathbf{i}_{r} & \text { Stator and rotor current space vectors. } \\ k & \text { Time instant } k .\end{array}$

Manuscript received December 12, 2017; revised February 7, 2018; accepted March 6, 2018. This work was supported by national funds through Fundação para a Ciência e a Tecnologia (FCT), with references UID/EEA/50008/2013 and UID/CEC/50021/2013.

S. M. A. Cruz and P. F. C. Gonçalves are with the Department of Electrical and Computer Engineering, University of Coimbra, and with Instituto de Telecomunicações, Pólo 2 - Pinhal de Marrocos, P-3030290 Coimbra, Portugal, (e-mail: smacruz@ieee.org, pgoncalves@ieee.org).

G. D. Marques is with the INESC-ID, Instituto Superior Técnico (IST), Universidade de Lisboa, Av. Rovisco Pais, no 1, 1049-001 Lisbon, Portugal (e-mail: gil.marques@tecnico.ulisboa.pt).

M. F. lacchetti is with the School of Electrical and Electronic Engineering, The University of Manchester, Manchester, M13 9PL, U.K. (e-mail: matteo.iacchetti@manchester.ac.uk).

$\begin{array}{ll}k_{T} & \text { Torque gain factor. } \\ L_{s}, L_{m}, L_{r} & \text { Stator, mutual, rotor inductance. } \\ p & \text { Pole pairs } \\ P_{i n v 0} & \text { Losses in the inverter at rotor rated current. } \\ R_{s}, R_{r} & \text { Stator and rotor resistances. } \\ \mathbf{S} & \text { Inverter switching state. } \\ S_{A}, S_{B}, S_{C} & \text { Switching functions of the three inverter legs. } \\ T & \text { Original torque demand. } \\ T_{e} & \text { Electromagnetic torque. } \\ T_{s} & \text { Sampling time. } \\ u_{d c} & \text { dc bus voltage. } \\ \mathbf{u}_{s}, \mathbf{u}_{r} & \text { Stator and rotor voltage space vectors. } \\ \theta_{r} & \text { Rotor electric position. } \\ \lambda_{f} & \text { Weighting factor. } \\ \sigma & \text { Total leakage factor. } \\ \Psi_{s}, \psi_{r} & \text { Stator and rotor flux linkage space vectors. } \\ \omega_{m} & \text { Rotor mechanical angular speed. } \\ \omega_{r} & \text { Rotor electric angular speed. }\end{array}$

Subscripts

$B \quad$ Base quantity.

$n \quad$ Rated value.

$s, r \quad$ Stator or rotor quantities.

p.u. Per-unit value.

\section{Superscripts}

* Reference value.

max Maximum admissible value.

opt Optimum value for maximum efficiency.

\section{INTRODUCTION}

$\mathrm{T}$ HE doubly-fed induction-generator dc system - otherwise referred to as DFIG-dc system, is a dc power generation apparatus which consists of a wound-rotor induction machine interfaced with a single downsized voltage source inverter (VSI) and a diode rectifier, both sharing the same dc-link connected to a dc power system. The VSI provides the required magnetizing current and control action - usually on the rotor side, and the rectifier is in charge of the main power transfer - generally through the stator. The concept was originated from the well-known ac DFIG largely used in wind energy conversion systems [1], with the intent of having a relatively cheap power electronics interface while allowing high-performance torque control and avoiding machine oversizing when operating with constant dc voltage and 
variable speed.

Most regulation techniques for frequency and torque in the DFIG-dc system rely on field oriented control. Field orientation is achieved by either using the estimated flux angle [2] or driving the control frame directly at constant frequency [3] - as in ac stand-alone DFIGs. When the DFIG-dc system feeds a stand-alone dc load rather than a dc grid, the torque set-point comes from an outer controller in charge of dcvoltage regulation [4]. Direct torque control based on either frame transformations or switching tables and avoiding current control chains is explored in [5] and [6] respectively.

Although the stator frequency set-point is free, the majority of control strategies just keep it constant at the rated value. Nonetheless, in order to minimize losses, the stator flux setpoint should be varied forcing flux weakening at low load levels [7]: under constant dc voltage this results in a frequency-wild operation.

The torque ripple originated by the flux and current harmonic interaction is the most severe drawback of the DFIG-dc system and is inherently associated with the presence of the uncontrolled rectifier. An early study reported in [8] for an ac stand-alone DFIG feeding non-linear loads proposed to compensate for the harmonics by operating the grid-side converter (GSC) as an active filter. As the DFIG-dc system does not include any GSC, the only way to implement an active filter is by adding an extra converter [9], or replacing the diode-bridge with a second VSI, which turns the system into a dual-VSI DFIG [10]-[11]. Twelve-pulse rectifiers are another viable option to tackle the harmonics at the source [12]. All these solutions need extra hardware and/or a custommade multi-phase DFIG [13], which makes the case for a DFIG less compelling over PM or induction generators with a fully-rated converter.

The last few years have seen several proposals being issued to address the torque ripple of the DFIG-dc system at the control level, preserving the cheapest possible power electronics. They are largely inspired to the strategies devised to improve performance of ac DFIGs operating under distorted grid voltage [14]-[15] or with non-linear loads [16]. In [14] Hu et al. have formalized control conditions required for different targets such as zero torque ripple, zero stator power ripple, sinusoidal stator or rotor currents. In DFIGs operating with distorted stator voltage like the DFIG-dc system these targets cannot be achieved simultaneously.

The first attempt to tackle the torque ripple in the DFIG-dc system was made in [17] using resonant controllers (RC) in the current control chain to improve the tracking of the instantaneous torque. Nian et al. [18] envisaged the implementation of direct RC signal injection in the $q$-axis rotor voltage command in order to by-pass the current control chain. A further refinement was then made in [19] using repetitive control in such a way as to compensate for all the harmonics in a single shot. The impact of harmonic decoupling terms in the current chain was then investigated in [20]. Effective though periodic control techniques are when running in on-spec conditions, they all require the knowledge of stator frequency, which makes the implementation for variable frequency operation extremely challenging. As a matter of fact, no results can be found in literature showing the performance of these controls when the DFIG-dc system is running with a variable frequency set-point. Predictive delay compensation [21] was proposed with the intent to overcome these limitations: here the idea is to correct the torque-ripple rejection signal in advance so as to compensate for the delay introduced by the current control chain. The algorithm works effectively even with off-spec reference frequency, but it has not been tested against dynamic changes in the reference frequency set-point. Furthermore, it still needs PI current controllers and related tuning issues particularly for the calibration of the advance time.

Ideally, in the DFIG-dc system, any torque ripple compensation strategy should be highly robust against frequency fluctuations, to effectively integrate flux weakening control aimed at minimizing losses [7]. To the authors' best knowledge, however, combining simultaneous torque ripple elimination and flux weakening control has not been tempted yet, being the frequency-insensitive torque-ripple mitigation method the most critical aspect for this integration to succeed.

Such a challenge is taken and addressed in this paper by proposing a new predictive torque and flux control strategy which regulates the instantaneous rotor flux and torque with a very fast dynamics. The method is studied and implemented for a dc grid-connected DFIG-dc system. However, it may be also valid for the stand-alone operation by introducing an additional dc voltage controller setting the reference torque.

In recent years, finite control set model predictive control has been widely reported in the literature for application in electric drive systems [22], where predictive torque (and flux) control (PTC) is the strategy that provides less torque ripple in comparison to predictive current control (PCC) [23]. Regarding the DFIG connected to a dc-microgrid, only a PCC strategy has been reported so far [24], where the authors have neither compensated the algorithm execution delay nor addressed the torque ripple compensation issue. Furthermore, [24] considers constant frequency operation and does not tackle the minimization of losses.

Unlike usual stator-flux based DTC controls for DFIG-dc systems, this paper uses the rotor flux as it is more convenient for predictive control, as discussed later on. The PTC algorithm devised in this paper predicts the optimal voltage space vector to minimize a cost function combining predicted rotor flux and torque errors. The rotor flux set-point is torquedependent and follows an optimal trend to minimize losses. The control algorithm includes dead-time and sampling-delay compensation features, and allows the DFIG-dc system to achieve torque-ripple free and improved efficiency operation at the same time.

After introducing the machine modelling and control strategy (Section II), the paper presents simulation and experimental results - Sections III and IV, proving that the predictive control achieves effective torque ripple compensation even at synchronism and under variable frequency operation.

\section{Predictive Torque And Rotor Flux Control}

\section{A. Rationale}

The core of the torque mitigation strategy proposed in this paper is a predictive control algorithm which eliminates the 
drawbacks of limited bandwidth of control loops based on PI regulators. With this method there is no need to implement resonant controllers for the torque-ripple compensating signal. In this work, the control system relies on a motor model to predict its future behavior and thus select in advance the optimal actuation to obtain the desired torque and flux behavior.

The predictive torque and flux control strategy here proposed allows the instantaneous torque to be accurately regulated thus suppressing low-order torque oscillations typical of the DFIG-dc system. In addition to the torque control and from a theoretical point of view, either the stator or rotor fluxes could be controlled. A reason for controlling the rotor flux instead of the stator flux is that the $5^{\text {th }}$ and $7^{\text {th }}$ harmonics are unavoidable in the stator currents, as they are introduced by the diode bridge rectifier which connects the stator windings to the dc bus. Due to the mathematical relation between the stator flux, stator currents and torque, a constant torque would imply a distorted stator flux with non-constant magnitude. This would necessarily increase the complexity of predictive control strategies based on torque and stator flux control, as in this category of control systems the amplitude of the flux under control is usually maintained constant or slowly-changing over time. This problem becomes irrelevant by controlling the rotor flux and torque.

\section{B. Control Layout}

The DFIG-dc system under study along with a general overview of the proposed control system is shown in Fig. 1. The rotor circuits of the DFIG are fed by a VSI that is connected to the dc-link while its stator circuits are connected to the same dc-link through a three-phase diode bridge rectifier. The VSI in the rotor side is in charge of the control which adjusts the rotor flux (and indirectly the stator frequency) and torque. The control is implemented in the rotor reference frame, and all the stator variables are transformed to that reference frame using the measured rotor position angle.

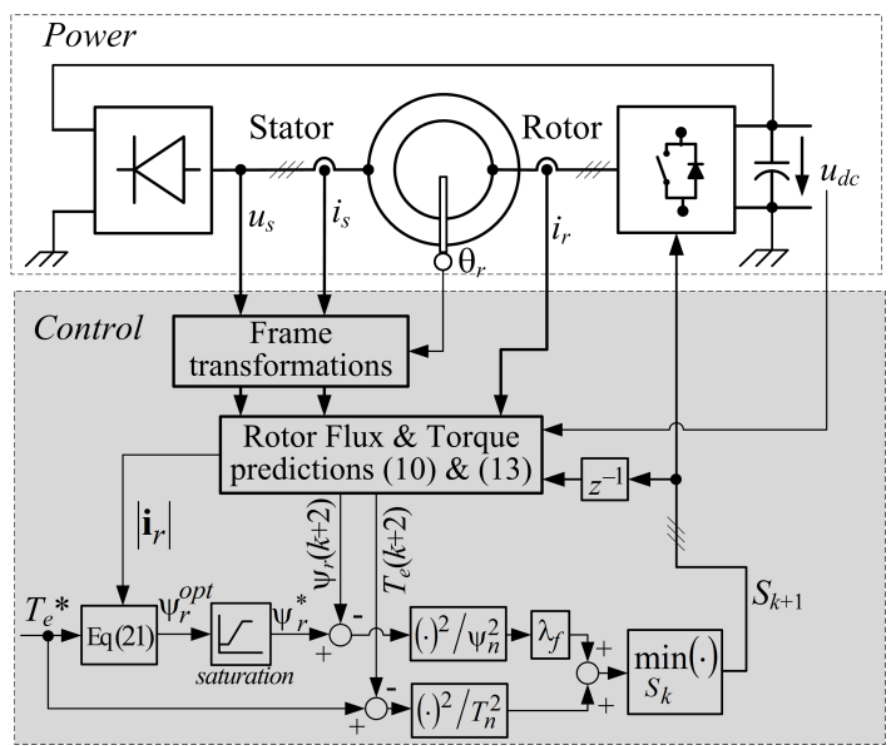

Fig. 1. System configuration and overall control scheme.

\section{DFIG Model}

The mathematical model of the DFIG is expressed in the rotor reference frame with all rotor quantities and parameters referred to the stator windings.

The stator and rotor voltage equations of the DFIG are:

$$
\begin{gathered}
\mathbf{u}_{s}=R_{s} \mathbf{i}_{s}+\frac{d}{d t} \boldsymbol{\psi}_{s}+j \omega_{r} \boldsymbol{\psi}_{s} \\
\mathbf{u}_{r}=R_{r} \mathbf{i}_{r}+\frac{d}{d t} \boldsymbol{\psi}_{r},
\end{gathered}
$$

and the stator and rotor fluxes are given by

$$
\begin{aligned}
& \boldsymbol{\psi}_{s}=L_{s} \mathbf{i}_{s}+L_{m} \mathbf{i}_{r} \\
& \boldsymbol{\psi}_{r}=L_{r} \mathbf{i}_{r}+L_{m} \mathbf{i}_{s} .
\end{aligned}
$$

The total leakage factor of the machine is defined as

$$
\sigma=1-\frac{L_{m}^{2}}{L_{s} L_{r}}
$$

By the manipulation of (3)-(4), the stator and rotor fluxes can be related by

$$
\boldsymbol{\psi}_{s}=\frac{L_{s}}{L_{m}}\left(\boldsymbol{\psi}_{r}-\sigma L_{r} \mathbf{i}_{r}\right) .
$$

The method to predict the rotor flux and torque is implemented in two steps. In the first step the flux is estimated using actual measurements and the algebraic flux-current relationship (4). In the second step, predictions are made by combining (1)-(2).

\section{Rotor Flux Estimation}

The rotor flux is estimated using the so called current model. It is based in the equation

$$
\boldsymbol{\psi}_{r}(k)=L_{r} \mathbf{i}_{r}(k)+L_{m} \mathbf{i}_{s}(k)
$$

This method is sensitive to parameter and rotor position measurement errors. However, it allows the system to operate in the entire speed range, including the synchronous speed.

\section{E. Prediction Model}

Combining (1), (2) and (6) gives the following equation for the rotor current

$$
\sigma L_{r} \frac{d \mathbf{i}_{r}}{d t}=\mathbf{u}_{r}-R_{r} \mathbf{i}_{r}-\frac{L_{m}}{L_{s}}\left(\mathbf{u}_{s}-R_{s} \mathbf{i}_{s}-j \omega_{r} \boldsymbol{\psi}_{s}\right) .
$$

A discrete model of the DFIG based on (2), (4), (6) and (8) can now be obtained using a forward Euler discretization method:

$$
\begin{aligned}
\mathbf{i}_{r}(k+1)= & \left(1-\frac{R_{r} T_{s}}{\sigma L_{r}}-j T_{s} \omega_{r}(k)\right) \mathbf{i}_{r}(k)+j \frac{T_{s}}{\sigma L_{r}} \omega_{r}(k) \boldsymbol{\psi}_{r}(k)+ \\
& \frac{T_{s}}{\sigma L_{r}} \mathbf{u}_{r}(k)-\frac{L_{m} T_{s}}{\sigma L_{r} L_{s}}\left(\mathbf{u}_{s}(k)-R_{s} \mathbf{i}_{s}(k)\right) \\
& \boldsymbol{\psi}_{r}(k+1)=\boldsymbol{\psi}_{r}(k)+\left(\mathbf{u}_{r}(k)-R_{r} \mathbf{i}_{r}(k)\right) T_{s},
\end{aligned}
$$

where $T_{s}$ represents the sampling time.

The rotor voltages in (9) and (10) are calculated using the measured dc bus voltage $u_{d c}(k)$ and the switching state of the 
inverter

$$
\begin{gathered}
\mathbf{u}_{r}(k)=u_{d c}(k) \frac{2}{3}\left(S_{A}(k)+e^{j 2 \pi / 3} S_{B}(k)+e^{-j 2 \pi / 3} S_{C}(k)\right) \\
\mathbf{S}(k)=\left[\begin{array}{lll}
S_{A}(k) & S_{B}(k) & S_{C}(k)
\end{array}\right]^{T}
\end{gathered}
$$

In (12), $S_{A}, S_{B}, S_{C}$ represent the switching functions of the three inverter legs, defined as $S_{\mathrm{x}}=1$ when upper switch is ON and lower switch is OFF, and $S_{\mathrm{x}}=0$ otherwise.

It should be noted that for rotor speeds close to the synchronous speed, the voltage applied to the rotor windings is very small. This fact, associated with the uncertainty in the value of the rotor resistance and with the voltage drop across the power switches of the inverter, would lead to rotor flux drift problems if the flux was calculated solely by (10), which is the discrete version of the voltage model given by (2). The solution to this problem lies in the use of the current model (7) for the calculation of $\boldsymbol{\psi}_{r}(k)$, using (10) only to estimate the rotor flux for the next time step. This solution is used over the entire speed range of the DFIG-dc system.

In order to increase the performance of the control system, particularly when the machine operates close to or at synchronous speed, the inverter dead-time is compensated using a similar approach to that adopted in [25].

Under motoring convention, the electromagnetic torque for instant $k+1$ can now be calculated using

$$
T_{e}(k+1)=-\frac{3}{2} p \boldsymbol{\psi}_{r}(k+1) \times \mathbf{i}_{r}(k+1) .
$$

To compensate the time delay between the sampling of the different quantities and the application of the new switching state to the inverter, a typical procedure, which is also adopted here, is to predict the quantities for instant $k+2$ and select the optimal actuation (rotor voltage vector) for instant $k+1$. Following this approach, the rotor current, rotor flux, and torque are estimated for instant $k+1$ using the measurements available at instant $k$. By using the one-sample-forward version of (9)-(10) and (13), the same quantities are then predicted for instant $k+2$ for each possible voltage vector the VSI can apply to the rotor. The optimal actuation (voltage vector) to be applied at instant $k+1$ is obtained by the minimization of the cost function discussed in the next subsection.

\section{F. Cost Function Design}

The cost function is defined considering two control goals: (i) regulate the amplitude of the rotor flux; (ii) impose a constant electromagnetic torque. The reference rotor flux $\psi_{r}^{*}$ regulates indirectly the stator frequency or, alternatively, allows the DFIG to be operated with minimum Joule losses due to the fundamental component of currents. The calculation of the optimal value of $\psi_{r}^{*}$ for a given torque demand is addressed in Section II-H. On the other hand, the torque reference $T_{e}^{*}$ regulates the active power sent to the dc bus by the DFIG stator.

A cost function $g$ is thus defined as

$$
g=\left(\frac{T_{e}^{*}-T_{e}(k+2)}{T_{n}}\right)^{2}+\lambda_{f}\left(\frac{\psi_{r}^{*}-\left|\boldsymbol{\psi}_{r}(k+2)\right|}{\psi_{n}}\right)^{2}
$$

where $T_{n}$ and $\psi_{n}$ represent the DFIG rated values of torque and flux. Furthermore, $\lambda_{f}$ is a suited weighting factor that regulates the importance of flux control over torque control and thus ensures an optimal control performance as far as torque and flux ripples are concerned. In (14), the torque and rotor flux for instant $k+2$ are predicted seven times, one for each one of the seven different voltage vectors the VSI can apply to the rotor windings. The VSI switching state corresponding to the voltage vector that minimizes the cost function is the one applied at instant $k+1$ :

$$
\mathbf{S}(k+1)=\arg \min _{\left\{\mathbf{S}_{1}, \ldots, \mathbf{S}_{7}\right\}}(g) .
$$

Fig. 2 summarizes the general flowchart of the calculations involved in the proposed control strategy.

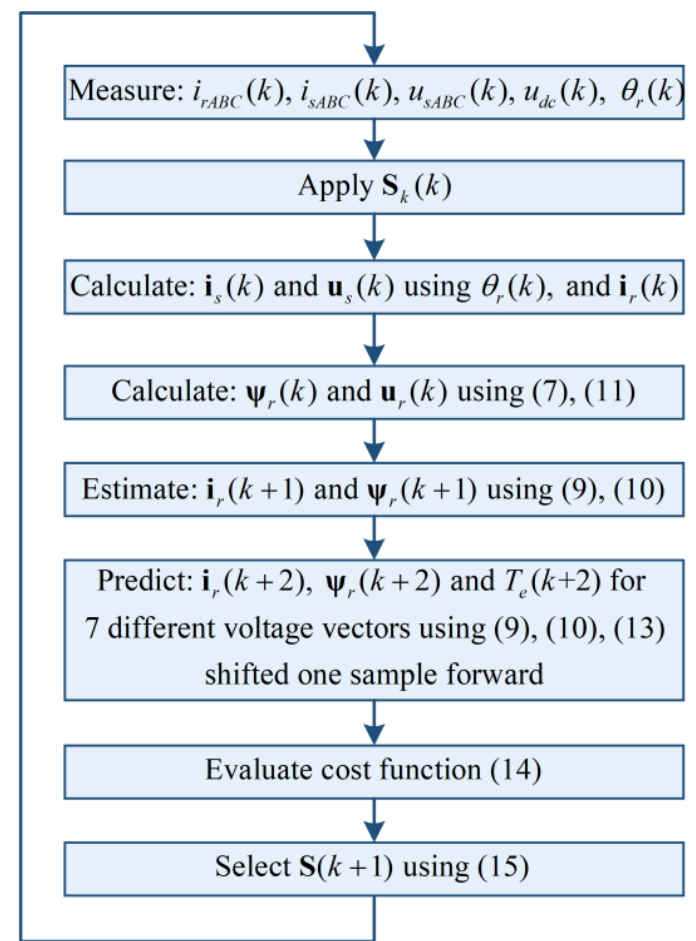

Fig. 2. Simplified flowchart of the proposed predictive control algorithm.

\section{G. Current limitation}

Predictive current control algorithms usually include a current limitation to ensure that under no circumstances the maximum current is exceeded. Typically, this is achieved by adding to the cost function an extra term which assumes a very high value for all the voltage vectors that lead to predicted current values above the current limit. Nevertheless, for predictive torque control algorithms and for this system in particular, this strategy proved to be not effective as the system tends to exhibit high torque and current ripples whenever the current is close to its limit. In some cases, the system was not able to limit the current at all, being this last case observed whenever all voltage vectors led to current values above the established limit. Following this, in the proposed control system the rotor current is limited indirectly by changing the original torque reference value $T^{*}$. The strategy consists in applying a low-pass filter $F(z)$ to the 
predicted rotor current $\left|\mathbf{i}_{r}(k+1)\right|$ followed by a saturator and a gain block, thus obtaining a torque value to be added (motor convention) to the original torque reference, according to

$$
\begin{gathered}
T_{e}^{*}=T^{*}+k_{T} \times \operatorname{sat}\left(F\left(\left|\mathbf{i}_{r}(k+1)\right|\right)-i_{r}^{\max }\right) \\
\operatorname{sat}(x)=\left\{\begin{array}{l}
0 \Leftarrow \mathrm{x} \leq 0 \\
x \Leftarrow \mathrm{x}>0
\end{array}\right.
\end{gathered}
$$

In (16), $i_{r}^{\max }$ represents the maximum admissible rotor

current. The torque gain $k_{T}$ can be chosen equal to the rated torque of the machine. With this procedure, the average current value is always maintained within the established limits without increasing the torque or flux ripples when the system operates close to its current limit.

\section{H. Optimum Rotor Flux Level}

For a given torque demand $T_{e}^{*}$, the reference rotor flux level in the DFIG $\left(\psi_{r}^{*}\right.$ in (14)) determines not only the stator frequency but also the losses of the DFIG-dc system. It was demonstrated in [7] that the sum of the DFIG Joule losses due to the fundamental component of currents and VSI conduction losses can be minimized by a proper choice of the stator flux level. The expression of the optimal stator flux magnitude for a given torque demand $T_{e}^{*}$ has been derived in [7] using perunit notation. The resulting expression in SI units is

$$
\psi_{s}^{o p t}=\sqrt{\frac{2 L_{s}}{3 p}\left|T_{e}^{*}\right|} \sqrt[4]{\frac{P_{i n v 0}+3\left(R_{s}+\left(\frac{L_{s}}{L_{m}}\right)^{2} R_{r}\right) \frac{L_{m}}{L_{s}} I_{B}\left|\mathbf{i}_{r}\right|}{P_{i n v 0}+3 R_{r} \frac{L_{s}}{L_{m}} I_{B}\left|\mathbf{i}_{r}\right|}}
$$

The background required for the derivation of (18) is resumed in Appendix I.

Based on the same theoretical foundations, the optimal stator flux level can be translated into an optimal rotor flux level $\psi_{r}^{o p t}$ to be used as a reference value in the predictive control algorithm. The derivation of $\psi_{r}^{\text {opt }}$ starts with the expression of the generic rotor flux space vector from (3)-(4)

$$
\boldsymbol{\psi}_{r}=\frac{L_{m}}{L_{s}} \boldsymbol{\psi}_{s}+\sigma L_{r} \mathbf{i}_{r}
$$

The magnitude $\psi_{r}$ of the rotor flux is obviously frameinvariant and can be obtained from (19) written in a reference frame conveniently aligned with $\psi_{s}$ :

$$
\psi_{r}=\left|\frac{L_{m}}{L_{s}} \psi_{s}+\sigma L_{r} \mathbf{i}_{r}\right|=\left|\frac{L_{m}}{L_{s}} \psi_{s}+\sigma L_{r}\left(\sqrt{\left.\mathbf{i}_{r}\right|^{2}-i_{r q}^{2}}+j i_{r q}\right)\right|
$$

When the generic magnitude $\psi_{s}$ in (20) is replaced by $\psi_{s}^{\text {opt }}$ provided by (18), and $i_{r q}$ is expressed in terms of torque and flux as $i_{r q}=2 L_{s} T_{e} /\left(3 p L_{m} \psi_{s}\right)-$ with $\psi_{s}=\psi_{s}^{o p t}$ and $T_{e}=T_{e}^{*}$, (20) gives the optimal rotor flux level

$$
\psi_{r}^{o p t}=\sqrt{\left(\frac{L_{m}}{L_{s}} \psi_{s}^{o p t}\right)^{2}+\left(\sigma L_{r}\left|\mathbf{i}_{r}\right|\right)^{2}+2 \sigma L_{r} \sqrt{\left(\psi_{s}^{o p t}\left|\mathbf{i}_{r}\right| \frac{L_{m}}{L_{s}}\right)^{2}-\left(\frac{2 T_{e}^{*}}{3 p}\right)^{2}}}
$$

The resulting expression (21) for $\psi_{r}^{o p t}$ still depends upon the rotor current magnitude $\left|\mathbf{i}_{r}\right|$, directly and through (18), and cannot be manipulated to eliminate $\left|\mathbf{i}_{r}\right|$ and get a closed-form expression for $\psi_{r}^{o p t}$ as a function of $T_{e}^{*}$ only. In the practical implementation, however, $\left|\mathbf{i}_{r}\right|$ in (18) and (21) can be directly measured, avoiding algebraic loops.

Maximum and minimum rotor flux conditions should also be included to limit magnetic saturation and maximum stator frequency, respectively. This is the purpose of the saturation block in Fig. 1.

\section{Simulation Results}

This section presents some simulation results comparing the performance of the proposed Predictive Torque Control with that of a Direct Torque Control based on PI controllers [5]. In order to allow cross validation, simulations use a detailed Matlab/Simulink model with the same parameters of the $4 \mathrm{~kW}$ Lab setup given in the Appendix II.

\section{A. System based on DTC with ordinary-bandwidth torque and flux controllers.}

The considered benchmark system is quite similar to the direct stator-flux and torque control [5]: this is not exactly a classic DTC since the control is performed in the stator-flux reference frame similarly to vector control. In the benchmark system, the main difference with respect to [5] is the use of the rotor flux instead of the stator one.

The simulation refers to a step on the reference torque, which is changed from -4 to $-25 \mathrm{Nm}$ while the DFIG is operated close to synchronism $\left(\omega_{m}=1.03\right.$ p. u. $)$. Rotor currents and flux are referred to the stator.

Fig. 3 shows the clear presence of torque ripples at 6 times the stator frequency. They are produced by diode commutations and, according to [5], they are smaller in this scheme than if field orientation were used. Although the control system concept would let think that the torque ripple could be eliminated, this is not the case because the bandwidth practically achievable in this system is not enough to compensate for the perturbations due to diode commutations in the stator. There are also flux oscillations that are much more evident in the stator than in the rotor: they are due to the distorted (quasi six-step) stator voltage, being the stator flux almost equal to the integral of the stator voltage. This is one of the reasons why the rotor flux was chosen to be the controlled flux. 

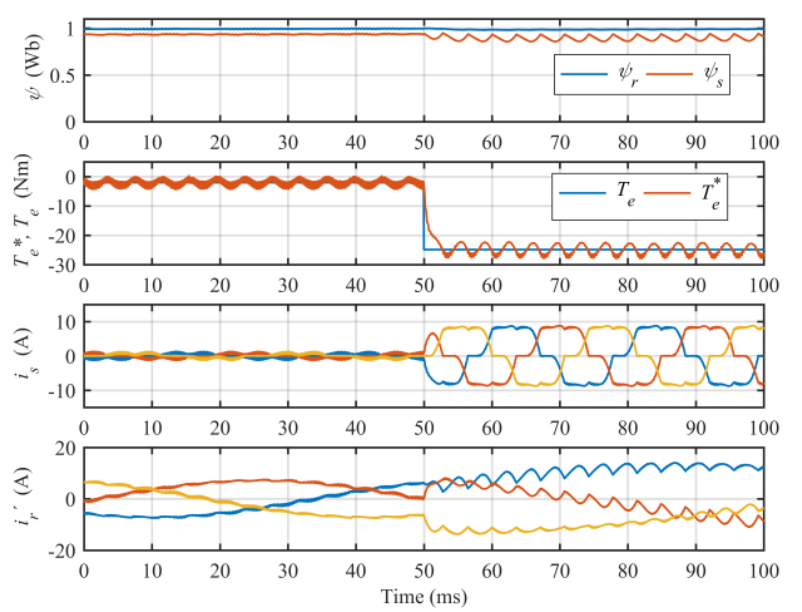

Fig. 3. Response to torque step variations using the DTC controller with ordinary bandwidth.

\section{B. Predictive control method with high bandwidth.}

Fig. 4 shows the simulation results with the control method presented in this paper and operating in the same conditions considered in Fig. 3. The weighting factor in (14) was set to $\lambda_{f}=2$ by trial and error. In this simulation, the optimal rotor flux command (21) was disabled, and the rated rotor flux was adopted as a reference value; simulation and experimental results with optimal flux command enabled are given in Fig. 6 and 11.

The torque ripple in Fig. 4 has now almost vanished. The stator flux waveform is similar to that in Fig. 3, but the stator and rotor current waveforms are now different because they are affected by the torque-ripple compensation.

The joule losses minimization is validated in Fig. 5 by varying the rotor-flux set-point manually instead of using (21). The torque reference was maintained constant at a low value ($6 \mathrm{Nm}$ ) and the rotor flux reference was gradually decreased from $1 \mathrm{~Wb}$ to $0.4 \mathrm{~Wb}$. Fig. 5 shows that when the rotor flux is equal to the optimum value (21) the sum of copper and VSI conduction losses is minimum.

Finally, Fig. 6 shows the performance with a variable torque reference at a constant speed of $1550 \mathrm{r} / \mathrm{min}$ with the optimal reference rotor flux (21) enabled. The figure reports stator and rotor flux magnitudes, electromagnetic torque and rotor currents in phase $A$. At low torque levels, the system works with automatic flux weakening regulation tracking the optimal reference flux given by (21), but at high torque levels (21) would exceed the rated flux value of $1 \mathrm{~Wb}$. For this reason, the reference flux is saturated at the rated flux value. Fig. 6 also shows that at low load the system has to operate with variable frequency.
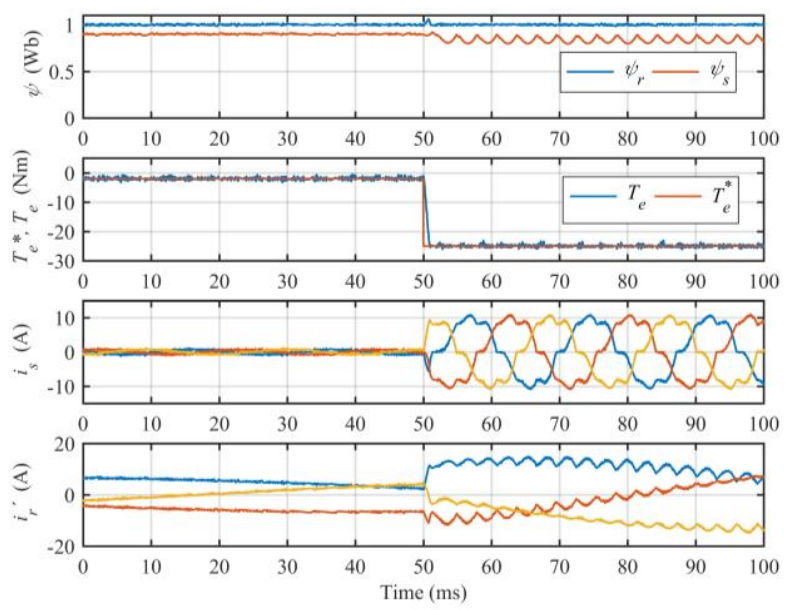

Fig. 4. Response to a step in the torque reference (predictive controller).
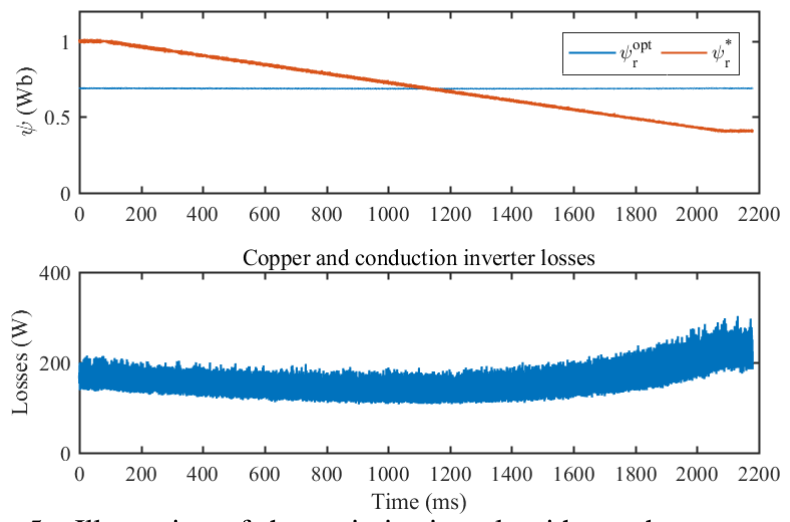

Fig. 5. Illustration of the optimization algorithm: when $\psi_{r}$ equals $\psi_{r}^{o p t}$, copper and VSI conduction losses are minimized.
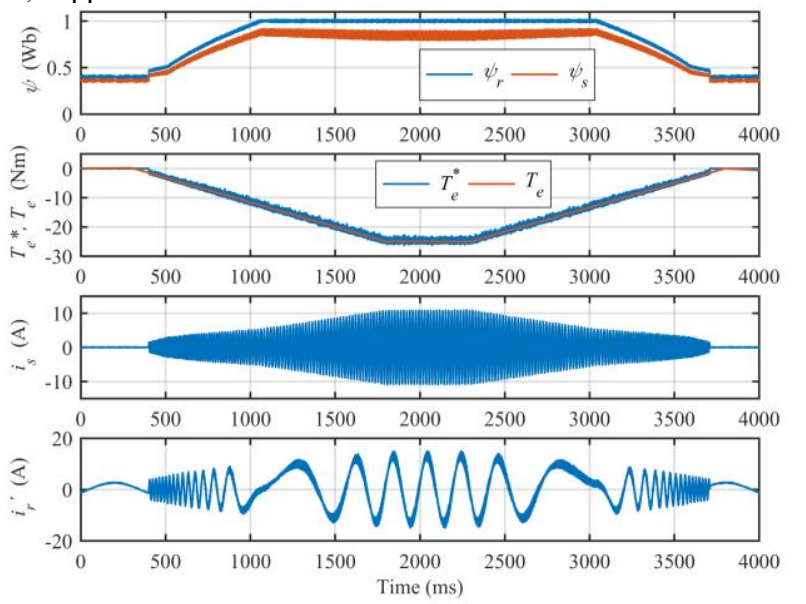

Fig. 6. Illustration of the optimization algorithm for a varying torque reference.

\section{EXPERIMENTAL RESULTS}

\section{A. Experimental Setup}

The DFIG-dc system used in the experimental tests, shown in Fig. 7, has the parameters listed in Appendix II. Because the DFIG stator and rotor rated voltages are different, a step-down autotransformer with a transformation ratio of $\sqrt{3}$ is connected between the stator windings and the three-phase diode bridge 
rectifier which feeds the $265 \mathrm{~V}$ dc-bus. This dc-voltage was obtained with the aid of an additional autotransformer, whose output voltages are rectified with a three-phase diode bridge and filtered using a $3400 \mu \mathrm{F}$ capacitor. The dc-bus was permanently feeding a resistor which dissipates a power always greater than the active power sent by the DFIG to the dc-bus, thus allowing the dc voltage to remain constant.

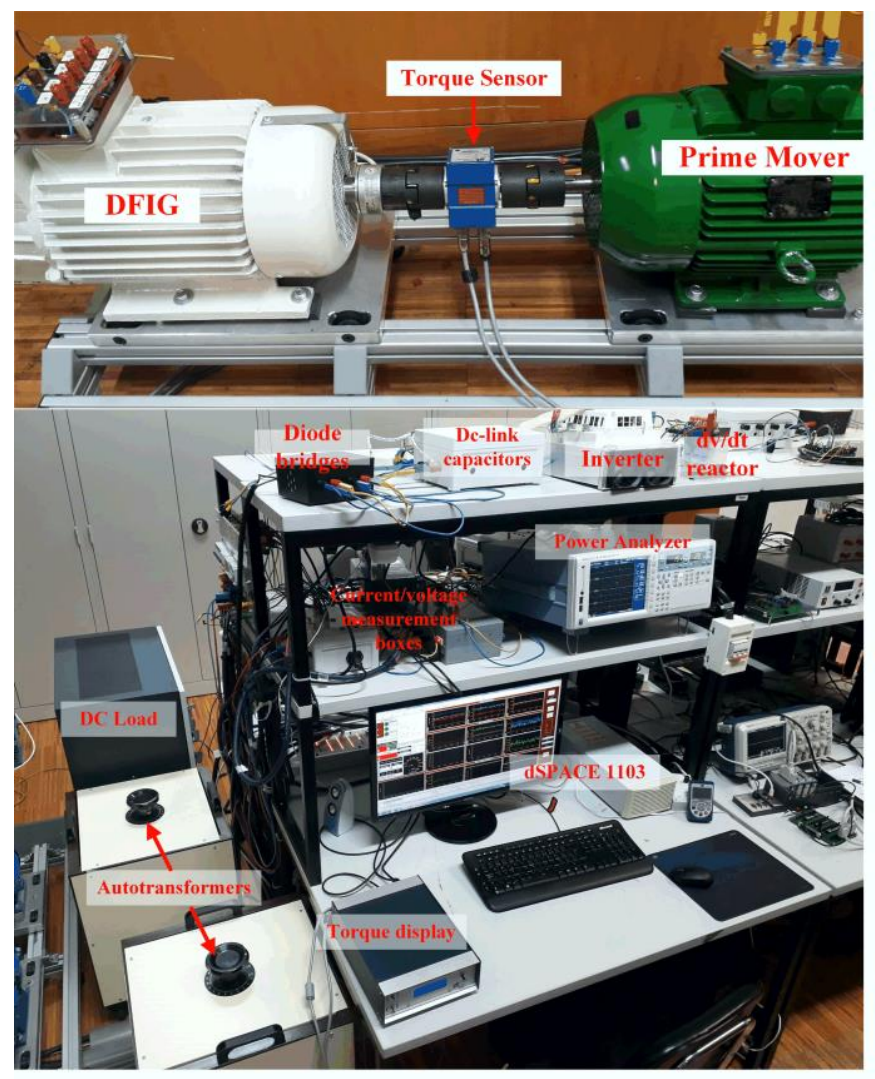

Fig. 7. Experimental test rig.

A two-level VSI fed by the dc-bus supplies the rotor windings of the DFIG. To protect the insulation system of these windings, a dv/dt reactor with an inductance of $2.6 \mathrm{mH}$ is connected between the inverter and the rotor windings. This inductance is taken into consideration by the control system by adding its inductance value to the rotor leakage inductance of the machine. The rotor position is measured with an incremental encoder with $1024 \mathrm{ppr}$.

The prime mover of the DFIG is an auxiliary $7.5 \mathrm{~kW}$ vector-controlled induction motor drive with the ability to operate in either torque or speed control mode (see Appendix II for the specs).

The control system was implemented in a dSPACE 1103 digital platform, with a sampling time of $50 \mu \mathrm{s}$. This platform was also used for sampling all currents/voltages of the system. A precision power analyzer Yokogawa WT3000 was used for monitoring purposes, in order to visualize the DFIG currents/voltages and the dc-bus quantities. Even if the setup includes a high-bandwidth torque sensor mounted on the shaft coupling, all the experimental results in the next subsections show the electromagnetic torque estimated by (13) - rewritten for instant $k$, which is more adequate to detect the torque ripple components. In fact, due to the low-pass filtering introduced by the rotor inertia, the mechanical torque is not an accurate replica of the electromagnetic torque and tends to be much smoother.

\section{B. Obtained Results}

Several experimental results are now shown to validate the proposed control system for the DFIG-dc system.

\section{1) Steady-State Operation}

Fig. 8 shows the results obtained when the DFIG operates in steady-state, with a torque level of $-12.5 \mathrm{Nm}$ and a rotor speed of $1350 \mathrm{r} / \mathrm{min}$.

As can be seen, the magnitude of the rotor flux is maintained constant, while the stator flux magnitude contains oscillations at the $6^{\text {th }}$ harmonic of the stator quantities. On the other hand, the electromagnetic torque is free from those oscillations, tracking closely the reference value. Fig. 9 shows the spectrum of the electromagnetic torque, proving that the torque is mainly constant and has a very low-order harmonic content. In fact, the amplitude of the residual $6^{\text {th }}$ harmonic is identical to other residual torque harmonic components, demonstrating that the elimination of torque harmonics - in particular at 300 and $600 \mathrm{~Hz}$, was accomplished. These results were also confirmed by the mechanical torque recorded with the torque sensor mounted on the DFIG shaft.

\section{2) Rotor Flux Level Optimization}

The optimization of the rotor flux level as a function of the torque reference is illustrated in Fig. 10. In order to minimize the losses in the DFIG-dc system, the flux level is lower for
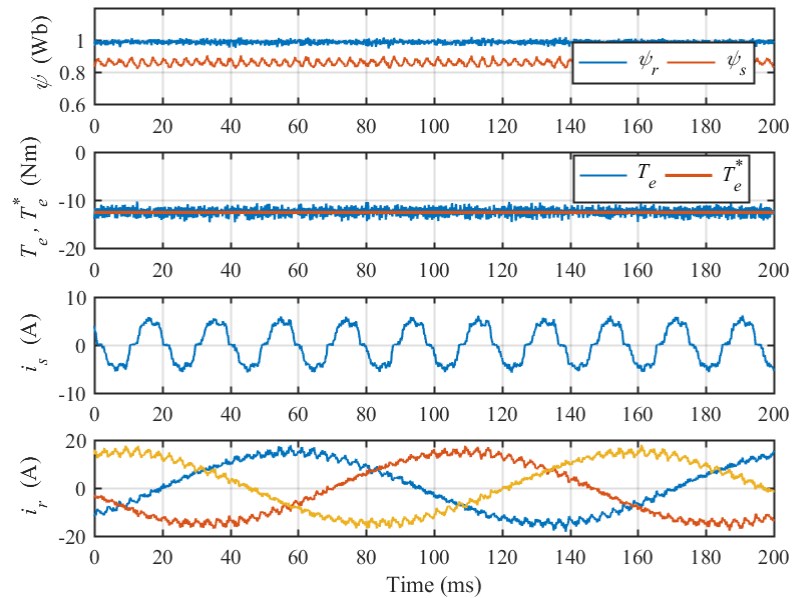

Fig. 8. Steady-state operation at $1350 \mathrm{r} / \mathrm{min}$.

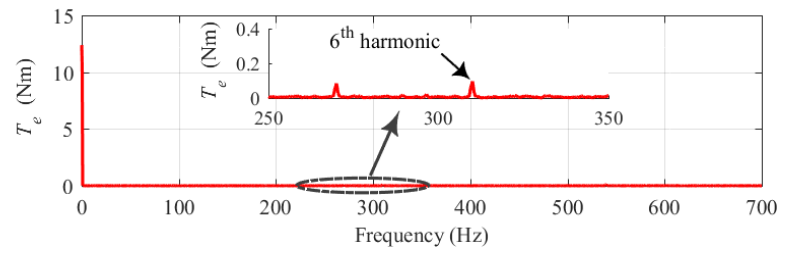

Fig. 9. Spectrum of the electromagnetic torque shown in Fig. 8. 

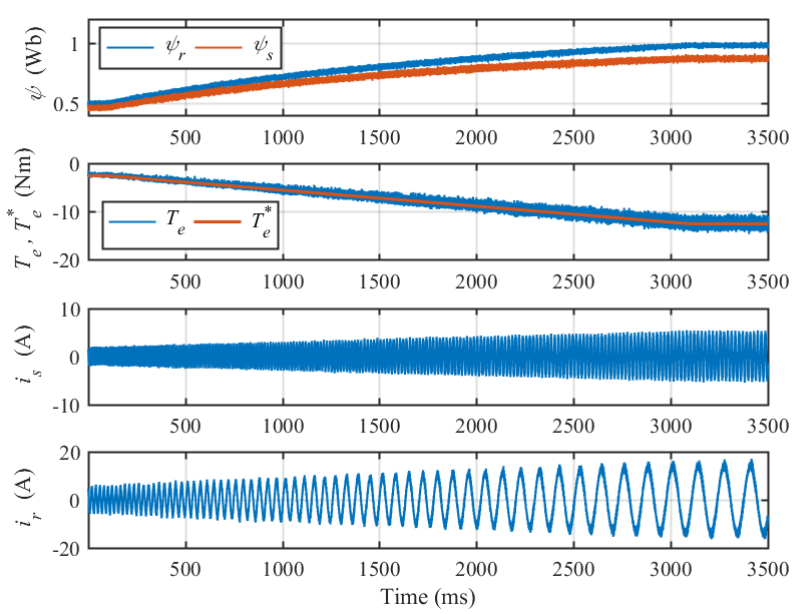

Fig. 10. Rotor flux level optimization. Rotor speed of $1350 \mathrm{r} / \mathrm{min}$.

lower torque levels while it increases up to the rated flux for higher torque values. These results demonstrate once again the absence of low-order torque oscillations and the ability of the system to operate correctly at different load levels.

\section{3) Torque Step Response}

The system response to a torque step variation is shown in Fig. 11. Even considering the need to increase the flux level in the machine, a torque step variation from -2.5 to $-12.5 \mathrm{Nm}$ leads to a torque rise time of only $2.5 \mathrm{~ms}$ without exhibiting any overshoot. This fast torque response is one of the attracting features of predictive control algorithms in general, being also confirmed in this system. To eliminate small ripples in the rotor flux reference, a first order low-pass filter with a cut-off frequency of $30 \mathrm{~Hz}$ is used. This influence is
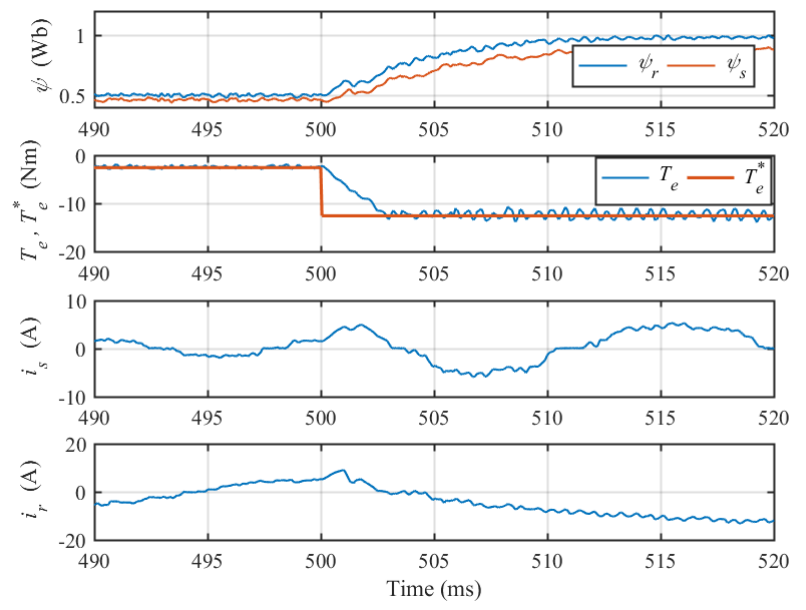

Fig. 11. Torque step response. Rotor speed of $1350 \mathrm{r} / \mathrm{min}$.

observable in the flux response as it is slower than the torque response.

\section{4) Rotor Speed Variation}

The response of the system when the rotor speed is ramped up between 1030 and $1750 \mathrm{r} / \mathrm{min}$, for a constant torque reference of $-12.5 \mathrm{Nm}$, is shown in Fig. 12. The rotor flux and torque of the machine are well regulated, independently of the rotor speed. The rotor frequency initially decreases until the machine reaches the speed of synchronism, and then increases for higher speeds. The system operates smoothly even at the synchronous speed, when the rotor currents are dc quantities.

\section{5) Operation at Synchronous Speed}

Fig. 13 shows the behavior of the system when operating with a torque reference of $-12.5 \mathrm{Nm}$ at rated rotor flux and zero rotor frequency during an extended period of time. The rotor speed $(1520 \mathrm{r} / \mathrm{min})$ is slightly different from $1500 \mathrm{r} / \mathrm{min}$ due to the tolerance in the value of the rated flux, making the stator frequency slightly higher than the rated $50 \mathrm{~Hz}$.

This figure shows clearly that, due to the characteristics of the flux estimator used, the method proposed here is valid for synchronous operation.

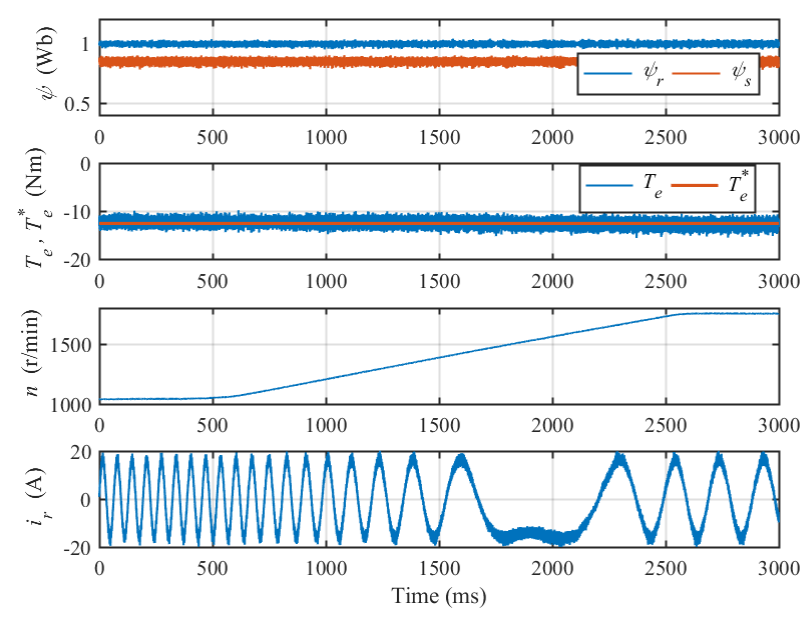

Fig. 12. Response to a speed ramp variation.
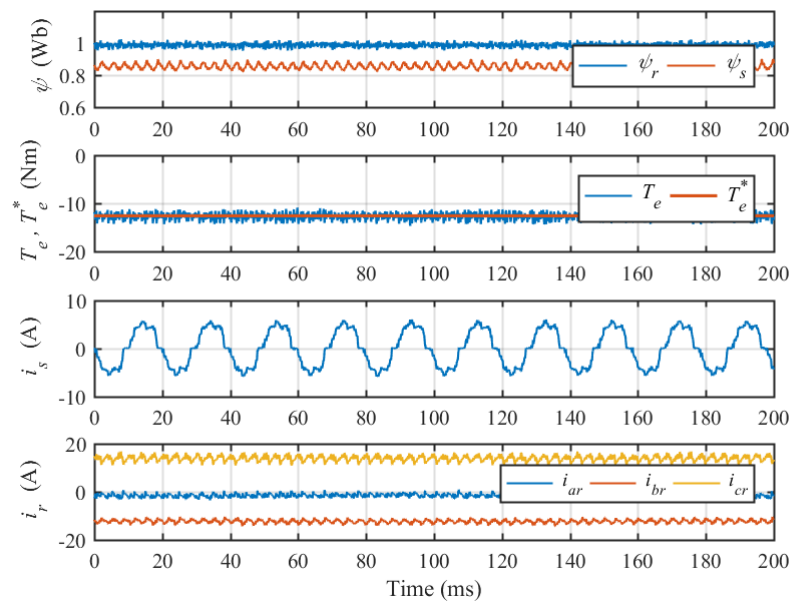

Fig. 13 Test at synchronous speed run for an extended period of time.

All these results combined demonstrate the ability of the system to perform very well both at steady-state and in transient conditions, allowing the torque ripple to be suppressed even when the system operates with variable frequency.

\section{6) Verification of Minimum Loss Operation}

In order to assess the soundness of the minimum-loss optimal rotor flux level given by (21), the simulation results in 
Fig. 5 were validated experimentally. The system was run with a variable reference rotor flux following a decreasing ramp instead of using (21). The DFIG Joule winding losses and the VSI conduction losses were indirectly evaluated from the measured currents, being presented in Fig. 14 along with the imposed rotor flux level and the (constant) optimal value predicted by (21) for the considered operating conditions. Fig. 14 clearly demonstrates that when the reference flux equals the optimal value given by (21) the aforementioned losses are at the minimum value. This also shows the importance of operating the DFIG with an adaptive flux level, in order to keep the losses to a minimum value.
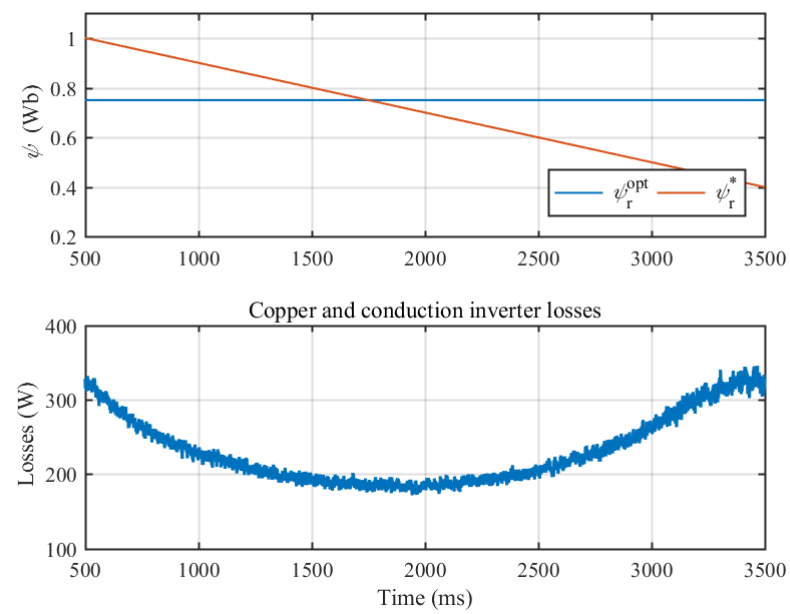

Fig. 14 Trend of the sum of copper and inverter conduction losses in the DFIG during a test with a linearly decreasing reference flux (DFIG operating with $-6 \mathrm{Nm}$ at $1350 \mathrm{r} / \mathrm{min}$ ).

\section{CONCLUSION}

This paper has addressed the elimination of the lowfrequency torque ripple in the DFIG-dc system by using a new predictive torque and rotor flux control strategy which allows very fast torque dynamics and consequent effective control of the instantaneous electromagnetic torque. Compared to periodic-control-based techniques for torque ripple mitigation, such as resonant and repetitive control, the strategy proposed in this paper incorporates three main novelties:

- it requires minimum tuning effort to reach the goal of eliminating diode-commutation related torque oscillations

- it is inherently insensitive to stator frequency variations

- the variable-frequency operation capability is exploited to regulate the rotor flux level at the optimal value in order to minimize Joule losses whilst preserving torque-ripple rejection.

Along with the full explanation of the control scheme, the paper includes the theoretical derivation of the optimal rotor flux level for minimizing DFIG main Joule losses and VSI conduction losses. As proved by the extensive simulation and experimental results, the proposed technique is able to eliminate the torque ripple even under variable frequency operation and keeps the overall Joule losses at minimum.

\section{APPENDIX I}

According to [7], by neglecting iron losses and using per- unit notation, the optimal stator flux level for a given torque demand $t_{e}^{*}$ is given by

$$
\psi_{s p u}^{o p t}=\sqrt{l_{s}\left|t_{e}^{*}\right|} \times \sqrt[4]{\frac{\tau+\lambda\left|\mathbf{i}_{R}\right|_{p u}}{\tau+\left|\mathbf{i}_{R}\right|_{p u}}}
$$

with

$$
\left\{\begin{array}{l}
\left|\mathbf{i}_{R}\right|_{p u}=\left|\mathbf{i}_{r}\right|_{p u} \times \frac{l_{m}}{l_{s}} ; \quad r_{R}=r_{r} \times\left(\frac{l_{s}}{l_{m}}\right)^{2} \\
\tau=\frac{p_{i n v 0}}{2 r_{R}} ; \lambda=\frac{r_{s}+r_{R}}{r_{R}} ; p_{i n v 0}=\frac{P_{i n v 0}}{\frac{3}{2} U_{B} I_{B}}
\end{array}\right.
$$

In (A1)-(A2), small caps are used for quantities expressed in per-unit, subscript $R$ denotes the rotor current and resistance referred to the $\Gamma$ equivalent circuit [7], and subscript $B$ denotes base quantities - peak stator rated voltage (phase) $U_{B}$ and current $I_{B}$. Furthermore, $P_{i n v 0}$ represents the conduction losses in the inverter when it supplies the DFIG rated rotor current. After replacing the definitions for per unit quantities $r_{x}=$ $R_{x} I_{B} / U_{B}, l_{x}=L_{x} \omega_{B} I_{B} / U_{B},\left|\mathbf{i}_{r}\right| p_{p u}=\left|\mathbf{i}_{r}\right| / I_{B}, t_{e}{ }^{*}=T_{e}{ }^{*} /\left(3 p U_{B} I_{B} / 2 \omega_{B}\right)$ in (A2) and (A1), the expression of $\psi_{s}^{\text {opt }}$ (18) is obtained.

\section{APPENDIX II}

Induction machine parameters: $4 \mathrm{~kW}$, 4-pole; stator: $400 \mathrm{~V}$, 9.4 A; rotor: $230 \mathrm{~V}, 11.5 \mathrm{~A} ; R_{s}=1.29 \Omega, R_{r}=1.31 \Omega, L_{s}=L_{r}$ $=144.1 \mathrm{mH}, L_{m}=136.2 \mathrm{mH}$.

Prime mover: $400 \mathrm{~V}, 7.5 \mathrm{~kW}$, 4-pole induction machine, controlled by a WEG CFW11 converter.

VSI and dv/dt filter: $P_{i n v 0}=100 \mathrm{~W}, L_{f}=2.6 \mathrm{mH}$.

\section{REFERENCES}

[1] R. Cárdenas, R. Peña, S. Alepuz, G. Asher, "Overview of control systems for the operation of DFIGs in wind energy applications," IEEE Trans. Ind. Electron., vol. 60, no. 7, pp. 2776-2798, July 2013.

[2] G. D. Marques, M. F. Iacchetti, "Stator frequency regulation in a field oriented controlled DFIG connected to a dc link," IEEE Trans. Ind. Electron., vol. 6, no. 11, pp. 5930-5939, Nov. 2014.

[3] H. Misra; A. Gundavarapu; A. K. Jain, "Control Scheme for DC Voltage Regulation of Stand-Alone DFIG-DC System," IEEE Trans. Ind. Electron., vol. 64, no. 4, pp. 2700-2708, Apr. 2017.

[4] H. Misra, A. K. Jain, "Analysis of Stand Alone DFIG-DC System and DC Voltage Regulation with Reduced Sensors," IEEE Trans Ind. Electron.., vol. 64, no. 6, pp. 4402-4412, June 2017.

[5] P. Maciejewski and G. Iwanski, "Direct Torque Control for Autonomous Doubly Fed Induction Machine based DC Generator," $12^{\text {th }}$ Int. Conf. on Ecological Vehicles and Renew. En. (EVER), Monaco, 2017, pp. 1-6.

[6] A. Gundavarapu, H. Misra, A. K. Jain, "Direct torque control Scheme for DC Voltage Regulation of Standalone DFIG-DC System," IEEE Trans Ind. Electron., Early Access Articles, 2017.

[7] G. D. Marques and M. F. Iacchetti, "Field-Weakening Control for Efficiency Optimization in a DFIG Connected to a DC-Link," in IEEE Trans. Ind. Electron., vol. 63, no. 6, pp. 3409-3419, June 2016.

[8] A. Kumar Jain, V.T. Ranganathan, "Wound Rotor Induction Generator with Sensorless Control and Integrate Active Filter for Feeding Nonlinear Loads in a Stand-Alone Grid," IEEE Trans. on Ind. Electron., vol. 55, No.1pp. 218 - 228, Jan. 2008.

[9] N. Yu, H. Nian, Y. Quan, "Novel de grid connected DFIG system with active power filter based on predictive current control," Electrical Machines and Systems Int. Conf. ICEMS 2011, 22-23 Aug 2011.

[10] Heng Nian, Yi Xilu, "Coordinated control strategy for doubly-fed induction generator with dc connection topology," IET Renew. Power 
Gener., vol. 9, no. 7, pp. 747-756, 2015.

[11] S. Yan, A. Zhang, H. Zhang, J. Wang, B. Cai, "Optimized and coordinated model predictive control sheme for DFIGs with DC-Based converter system," J. Mod. Power Syst. Clean Energy, 5: 620, 2017.

[12] R. D. Shukla, R. K. Tripathi, P. Thakur, "DC grid/bus tied DFIG based wind energy system," in Renewable Energy 108 (2017) pp. 179-193.

[13] P. Maciejewski, G. Iwanski, "Modeling of Six-Phase Double Fed Induction Machine for Autonomous DC Voltage Generation," $10^{\text {th }}$ Int. Conf. on Ecological Vehicles and Renew. En. (EVER), 2015, Monaco.

[14] J. Hu, H. Nian, H. Xu, and Y. He, "Dynamic modeling and improved control of DFIG under distorted grid voltage conditions," IEEE Trans.Energy Convers., vol. 26, no. 1, pp. 163-175, Mar. 2011.

[15] H. Xu, J. Hu, and Y. He, "Operation of wind-turbine-driven DFIG systems under distorted grid voltage conditions: Analysis and experimental validations," IEEE Trans. Power Electron., vol. 27, no. 5, pp. 2354-2366,May 2012.

[16] Van-Tung Phan, Hong-Hee Lee, "Control strategy for harmonic elimination in stand-alone DFIG applications with nonlinear loads," IEEE Trans. Pow. Electron, vol. 26, no. 9, Sept. 2011, pp. 26622675.

[17] M. F. Iacchetti, G. D. Marques and R. Perini, "Torque ripple reduction in a DFIG-DC system by resonant current controllers," IEEE Trans. Power Electron., vol. 30, no. 8, pp. 4244-4254, Aug. 2015.

[18] H. Nian, C. Wu, P. Cheng, "Direct Resonant Control Strategy for Torque Ripple Mitigation of DFIG Connected to DC Link through Diode Rectifier on Stator," IEEE Trans. Pow. Electron., vol. 32, no. 9, pp. 6936-6945, Sept. 2017.

[19] C. Wu, H. Nian, "An Improved Repetitive Control of DFIG-DC System for Torque Ripple Suppression," IEEE Trans Power Electron. Early access articles 2017

[20] H. Misra and A. K. Jain, "Mathematical Modelling and Control of Standalone DFIG-DC system in rotor flux reference frame," in IEEE Trans. Ind. Electron., vol. 65, no. 5, pp. 3708-3717, May 2018.

[21] G. D. Marques, M. F. Iacchetti, "Minimization of torque ripple in the DFIG-DC system via predictive delay compensation," IEEE Trans. Ind. Electron., vol. 65, no. 1, pp. 103-113, Jan. 2018.

[22] F. Wang, X. Mei, J. Rodriguez, and R. Kennel, "Model predictive control for electrical drive systems-an overview," CES Transactions on Electrical Machines and Systems, vol. 1, pp. 219-230, 2017.

[23] Wang, S. Li, X. Mei, W. Xie, J. Rodríguez, and R. M. Kennel, "ModelBased Predictive Direct Control Strategies for Electrical Drives: An Experimental Evaluation of PTC and PCC Methods," IEEE Transactions on Industrial Informatics, vol. 11, pp. 671-681, 2015.

[24] Bayhan, H. Abu-Rub, and O. Ellabban, "Sensorless model predictive control scheme of wind-driven doubly fed induction generator in $\mathrm{dc}$ microgrid," IET Renewable Power Generation, vol. 10, pp. 514-521, 2016.

[25] A. Imura, T. Takahashi, M. Fujitsuna, T. Zanma, and S. Doki, "Deadtime compensation in model predictive instantaneous-current control," in IECON 2012 - 38th Annual Conference on IEEE Industrial Electronics Society, 2012, pp. 5037-5042.
Sérgio M. A. Cruz (S'96-M'04-SM'16) received the Electrical Engineering diploma, the M.Sc. and Dr. Eng. degrees in electrical engineering from the University of Coimbra, Coimbra, Portugal, in 1994, 1999, and 2004, respectively.

$\mathrm{He}$ has been with the Department of Electrical and Computer Engineering, University of Coimbra, where he is currently an Assistant Professor and the Director of the Electric Machines Laboratory. He is the author of more than 90 journal and conference papers in his field of research.

His teaching and research interests include power transformers, rotating electric machines, electric drives, and power electronic converters, with special emphasis on fault diagnosis, fault tolerance, and digital control.

Gil D. Marques (M'95-SM'12) was born in Benedita, Portugal, on March 24, 1958. He received the Dipl. Ing. and Ph.D. degrees in electrical engineering from the Technical University of Lisbon, Lisbon, Portugal in 1981 and 1988, respectively.

Since 1981, he has been with the Instituto Superior Técnico, University of Lisbon, where he involves in teaching power systems in the Department of Electrical and Computer Engineering. He has been an Associate Professor since 2000. He is also a Researcher at INESCID.

His current research interests include electrical machines, static power conversion, variable-speed drive and generator systems, harmonic compensation systems and distribution systems.

Pedro F. C. Gonçalves (S'17) was born in Coimbra, Portugal, in 1990. He received the M.Sc. degree in Electrical and Computer Engineering from the University of Coimbra, Coimbra, Portugal in 2013.

Currently, he is working towards the Ph.D. degree at the Department of Electrical and Computer Engineering, University of Coimbra and he is also a researcher of the Power Systems research group at Instituto de Telecomunicações, Coimbra.

His research interests are focussed on control, fault-diagnosis and fault-tolerant control of electrical drives, applied to wind energy conversions systems.

Matteo F. lacchetti (M'10-SM'17) received the Ph.D. in electrical engineering from the Politecnico di Milano, Milano, in 2008.

From 2009 to 2014, he has been a Postdoctoral Researcher with the Dipartimento di Energia, Politecnico di Milano. He is currently a Lecturer with the School of Electrical and Electronic Engineering, at The University of Manchester, Manchester, U.K.

His main research interests include design, modelling, and control of electrical machines and electrical drives for power conversion. 